\title{
Association of the Prognosis and the Facial Nerve Enhancement in Gadolinium Enhanced MRI in Patients with Bell's Palsy
}

\author{
Hyuck Jae Lee, Seon Ik Kim, Jung Mee Park, and Kyoung Ho Park \\ Department of Otolaryngology-Head and Neck Surgery, College of Medicine, The Catholic University of Korea, Seoul, Korea
}

\author{
특발성 안면신경마비 환자에서 가돌리늄 조영증강 자기공명영상에서의 얼굴신경 신호강도와 예후의 관계 \\ 이혁재 · 김선익 · 박정미 · 박경호 \\ 가톨릭대학교 의과대학 이비인후과학교실
}

Received August 25, 2017

Revised September 8, 2017

Accepted September 9, 2017

Address for correspondence

Kyoung Ho Park, MD, PhD

Department of Otolaryngology-

Head and Neck Surgery,

College of Medicine,

The Catholic University of Korea,

222 Banpo-daero, Seocho-gu,

Seoul 06591, Korea

Tel $+82-2-2258-6213$

Fax $+82-2-595-1354$

E-mail khpent@catholic.ac.kr
Background and Objectives This study aimed to investigate the association of prognosis and facial nerve signal intensity in enhanced magnetic resonance imaging (MRI) in patients with Bell's palsy.

Subjects and Method Patients who visited hospital for Bell's palsy from January of 2015 to June of 2016 were included in this study. A total of 30 patients were gathered and their facial palsy grades were evaluated with the House-Brackmann grade system on the initial visit and at six months after the first visit. In T1-weighted MRI, we measured the signal intensity of the region of interest (ROI), or the most-highly-enhanced portion of the affected facial nerve and the corresponding portion of the contralateral side. We calculated the ratio of ROI of the affected side to the contralateral side, and investigated the correlation between the ratio and the degree of improvement in facial palsy.

Results The most frequent ROI of the affected facial nerve was labyrinthine segment. There was no significant correlation between the ROI ratio and initial H-B grade, or the degree of improvement in facial palsy.

Conclusion This study corresponds with the previous studies that indicated that the degree of the gadolinium enhancement of facial nerve in T1-weighted MRI is not related to the prognosis or the severity of the Bell's palsy.

Korean J Otorhinolaryngol-Head Neck Surg 2017;60(12):621-5

Key Words Bell's palsy · Facial nerve $\cdot$ Magnetic resonance imaging.

\section{서 론}

안면신경마비 중 가장 많은 형태인 특발성 안면신경마비(idiopathic facial palsy, Bell's palsy)는 매년 10만 명당 20 30 명이, 또는 일생 동안 60 70명 중 1명 꼴로 발생한다고 보고 되고 있다. ${ }^{1)}$ 발생 원인은 현재까지는 명확히 밝혀지지 않았으

This is an Open Access article distributed under the terms of the Creative Commons Attribution Non-Commercial License (http://creativecommons.org/licenses/by-nc/4.0) which permits unrestricted non-commercial use, distribution, and reproduction in any medium, provided the original work is properly cited.
며, 환자의 혈청에서 바이러스가 분리된 적은 없으나 임상 증 상과 바이러스 항체 역가의 변화를 토대로 바이러스 감염을 가장 유력한 원인으로 추정하고 있다.

특발성 안면신경마비의 병태생리학적인 기전으로는 감염 으로 인한 신경 내 염증 변화로 분절 탈수초 형성(segmental demyelination)이 일어나고 이에 속발한 부종이 안면신경관 (facial canal) 내의 신경을 압박하여 안면신경마비가 발생하 는 것으로 추정되고 있으며, 해부학적으로도 신경 내 병변의 부위를 확인할 수 있음이 보고된 바 있다. 이 중 특히 미로분 
절과 내이도분절에서 탈수초가 가장 심한 것으로 보고되었 으며, ${ }^{2)}$ 치료에 대해서는 아직 논란이 있는 상태로 불완전 마 비 형태의 특발성 안면신경마비는 치료하지 않으면 전체 환자 의 $6 \%$ 에서만 경미한 마비를 남기고 $94 \%$ 에서 완전회복되고, 완전마비 형태의 경우 완전회복이 $71 \%$, 경미한 장애가 $13 \%$, 중등도 및 고도의 안면신경 장애가 $16 \%$ 라고 알려져 있으나 이러한 데이터만으로 각 개인의 예후를 예측하기는 쉽지 않은 것이 현실이다. ${ }^{3,4)}$

일반적으로 자기공명영상(magnetic resonance imaging) 은 골 조직이 아닌 측두골 내부의 연부 조직과 특히 신경을 보 다 자세히 관찰할 수 있는 방법으로, 조영제로 사용되는 가돌 리늄(gadolinium)은 주로 세포 외액에 분포하게 되어 종양 이나 염증, 부종 등 세포 외액이 증가되는 상황에서 강하게 조 영증강 된다. ${ }^{5-8)}$ 안면신경마비 환자에서 시행한 가돌리늄 조영 증강 자기공명영상에서 안면신경의 일부에서 조영증강이 되 는 현상은 염증에 의한 혈관-신경 장벽의 붕괴로 인한 가돌 리늄의 혈관 투과성 증가의 결과로 나타나게 된다. ${ }^{9-11)}$ 그러나 최근 문헌들에 따르면, 신호강도의 증강은 안면마비의 정도, 안면신경 전기검사 결과, 예후와 연관성이 없는 것으로 보고 된 바 있어, 본 연구에서는 특발성 안면신경마비로 내원한 환 자군에서 시행한 자기공명영상의 신호강도와 예후와의 연관 관계를 보다 다각적으로 검증하고자 한다.

\section{대상 및 방법}

2015년 1월 1일부터 2016년 6월 30일까지 가톨릭대학교 서 울성모병원 이비인후과에 안면의 편측 마비를 주소로 내원하 여 특발성 안면신경마비로 진단된 후 경구 스테로이드 제제 치 료를 받으며 자기공명영상검사를 시행한 환자군 30명(남 13명, 여 17명)을 후향적으로 고찰하였다.
측두골 자기공명영상은 $1 \mathrm{~mm}$ 두께 영상으로 1.5-Tesla 영 상(Magnetom Vision Plus; Siemens, Erlangen, Germany) 을 사용하였으며 조영제로는 gadopentetate dimeglumine을 이용하였고, 용량은 $0.1 \mathrm{mmol} / \mathrm{kg}$ 을 정맥 주사하였다. 조영증 강된 부위는 안면신경의 다섯 분절, 즉 내이도분절, 미로분 절, 슬상신경절, 고실분절 및 유양동분절에서의 증강 여부를 관찰하였다. 경구 스테로이드 제제는 총 10 일간 사용하였으며 체중을 고려하여 남성의 경우 최고용량 prednisolone $60 \mathrm{mg} /$ day 5일간, 여성의 경우 최고용량 prednisolone $50 \mathrm{mg} /$ day 5 일 간 사용 후 5 일간 감량한 뒤 중지하였다. 양측이거나 의인성, 기저질환으로 인해 경구 스테로이드 제제 치료를 받지 못한 경우, 차트기록이 미비한 경우는 대상군에서 제외하였다. 특 발성 안면신경마비로 내원한 환자들의 안면마비의 정도는 초 진 시와 6개월 뒤 각각 House-Brackmann grade system으 로 평가되었다(Fig. 1A).

$\mathrm{T} 1$ 가돌리늄 조영증강 자기공명영상검사에서 병측 안면신 경부의 최대 조영증강 부위와 건측 동일 부위를 region of interest(ROI)로 설정하여 이 부위들의 조영증강 정도를 측정 하였다(Fig. 1B). 측정한 값으로 병측과 건측의 ROI 조영증강 도의 비(ratio)를 구하여 이 값을 해당 환자의 조영증강 자기공 명영상검사에서의 신호강도로 정의하였으며, $\mathrm{ROI}$ 의 ratio와 안면마비 예후와의 연관관계를 통계학적으로 분석하였다.

본 연구는 서울성모병원 임상연구심의위원회(KCMC IRB) 의 승인을 받아 진행하였다(승인번호: KC17RESI0749).

\section{결 과}

특발성 얼굴신경마비 환자의 평균 나이는 $52.3 \pm 12.7$ 세였으 며 남녀비는 1.0:1.4였다. 우측에서 발생한 경우가 16 명, 좌측 이 14 명이었다. 환자들의 최초 내원 당시 측정한 $\mathrm{H}-\mathrm{B}$ grade의
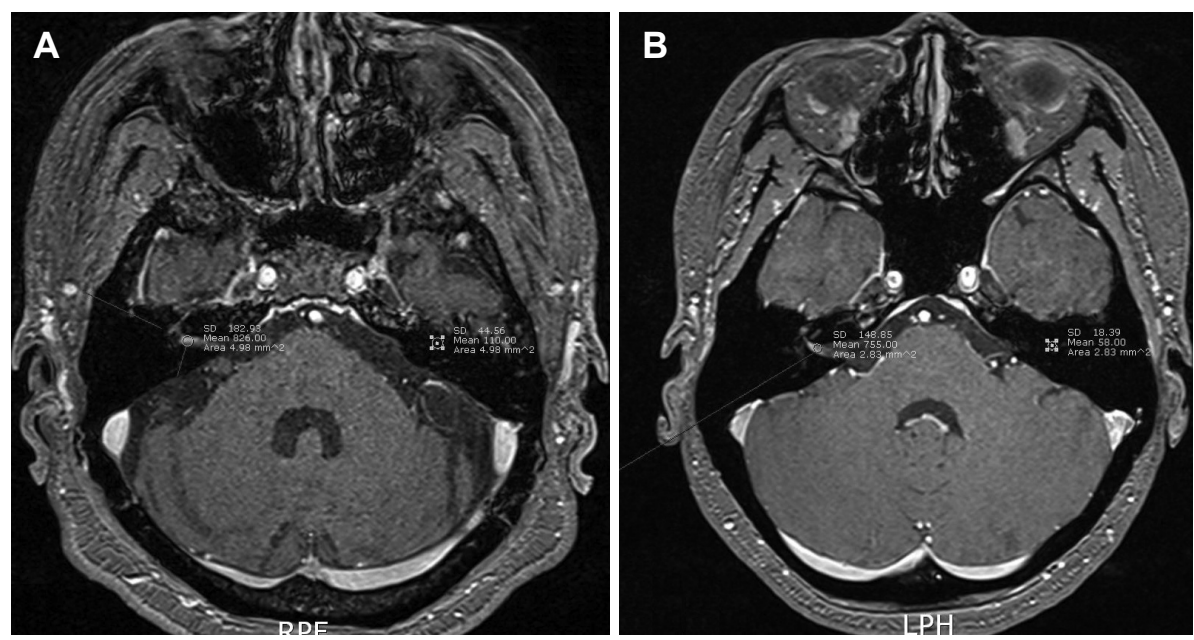

Fig. 1. Examples showing how to measure the region of interest of the affected side in this article ( $A$ and $B$ ). 
Table 1. Clinical characteristics and measured data of the patients

\begin{tabular}{|c|c|c|c|c|c|c|c|c|c|c|}
\hline $\begin{array}{c}\text { Patient } \\
\text { no. }\end{array}$ & $S / A$ & Side & $\begin{array}{l}\text { Affected } \\
\text { portion }\end{array}$ & $\begin{array}{l}\text { Days to } \\
\text { imaging }\end{array}$ & $\begin{array}{l}\text { Enhance } \\
\text { (affected) }\end{array}$ & $\begin{array}{r}\text { Enhance } \\
\text { (normal) }\end{array}$ & $\begin{array}{l}\mathrm{ROI} \\
\text { ratio }\end{array}$ & $\begin{array}{l}\text { Initial } \\
\text { H-B }\end{array}$ & $\begin{array}{l}6 \mathrm{~m} \\
\mathrm{H}-\mathrm{B}\end{array}$ & $\begin{array}{c}\text { Degree of } \\
\text { improvement }\end{array}$ \\
\hline 1 & $M / 61$ & $R$ & $T$ & 5 & 1286 & 35 & 36.74 & 3 & 1 & 2 \\
\hline 2 & $F / 48$ & L & $T$ & 1 & 471 & 165 & 2.85 & 2 & 2 & 0 \\
\hline 3 & $M / 61$ & L & $G$ & 5 & 538 & 380 & 1.42 & 4 & 2 & 2 \\
\hline 4 & $F / 43$ & $R$ & L & 7 & 376 & 293 & 1.28 & 4 & 2 & 2 \\
\hline 5 & $M / 46$ & $R$ & L & 2 & 325 & 287 & 1.13 & 3 & 1 & 2 \\
\hline 6 & $M / 58$ & $R$ & L & 10 & 459 & 284 & 1.62 & 4 & 3 & 1 \\
\hline 7 & $F / 59$ & L & L & 12 & 411 & 337 & 1.22 & 3 & 3 & 0 \\
\hline 8 & $M / 74$ & L & L & 2 & 443 & 264 & 1.68 & 4 & 1 & 3 \\
\hline 9 & $F / 58$ & $R$ & G & 1 & 836 & 324 & 2.58 & 3 & 2 & 1 \\
\hline 10 & $F / 42$ & $\mathrm{R}$ & $G$ & 6 & 358 & 301 & 1.19 & 4 & 2 & 2 \\
\hline 11 & $M / 67$ & L & L & 2 & 489 & 436 & 1.12 & 4 & 1 & 3 \\
\hline 12 & $\mathrm{~F} / 58$ & L & $\mathrm{T}$ & 3 & 661 & 629 & 1.05 & 3 & 1 & 2 \\
\hline 13 & $\mathrm{~F} / 44$ & $\mathrm{R}$ & $\mathrm{T}$ & 2 & 1465 & 813 & 1.80 & 5 & 4 & 1 \\
\hline 14 & $F / 32$ & $\mathrm{R}$ & L & 4 & 755 & 58 & 13.02 & 3 & 2 & 1 \\
\hline 15 & M/52 & L & $G$ & 5 & 944 & 814 & 1.16 & 4 & 2 & 2 \\
\hline 16 & $\mathrm{~F} / 55$ & L & G & 2 & 569 & 164 & 3.47 & 3 & 1 & 2 \\
\hline 17 & $\mathrm{~F} / 50$ & L & L & 6 & 1025 & 269 & 3.81 & 3 & 1 & 2 \\
\hline 18 & $M / 41$ & L & L & 8 & 1084 & 64 & 16.94 & 3 & 1 & 2 \\
\hline 19 & $\mathrm{~F} / 50$ & L & L & 5 & 828 & 526 & 1.57 & 5 & 4 & 1 \\
\hline 20 & M/70 & $R$ & L & 9 & 826 & 110 & 7.51 & 4 & 3 & 1 \\
\hline 21 & $F / 45$ & $R$ & G & 3 & 768 & 419 & 1.83 & 3 & 1 & 2 \\
\hline 22 & $F / 51$ & L & $G$ & 4 & 950 & 427 & 2.22 & 4 & 3 & 1 \\
\hline 23 & $F / 76$ & L & $G$ & 3 & 416 & 154 & 2.70 & 4 & 1 & 3 \\
\hline 24 & $M / 50$ & $\mathrm{R}$ & L & 8 & 1109 & 1069 & 1.04 & 3 & 2 & 1 \\
\hline 25 & $\mathrm{~F} / 52$ & L & $G$ & 12 & 676 & 549 & 1.23 & 3 & 1 & 2 \\
\hline 26 & $M / 54$ & $R$ & L & 5 & 353 & 350 & 1.01 & 3 & 2 & 1 \\
\hline 27 & $M / 33$ & $R$ & L & 7 & 473 & 195 & 2.43 & 2 & 1 & 1 \\
\hline 28 & $F / 29$ & L & L & 10 & 616 & 578 & 1.07 & 2 & 1 & 1 \\
\hline 29 & $\mathrm{~F} / 77$ & L & $M$ & 3 & 1001 & 472 & 2.12 & 5 & 1 & 4 \\
\hline 30 & $M / 33$ & $R$ & L & 7 & 503 & 269 & 1.87 & 2 & 1 & 1 \\
\hline
\end{tabular}

S/A: sex/age, Initial H-B: House-Brackmann grade at initial visit, $6 \mathrm{~m} \mathrm{H-B}$ : House-Brackmann grade 6 months later, M: male, F: female, R: right, L: left, T: tympanic, G: geniculate ganglion, L: labyrinthine, M: mastoid

Table 2. Frequency of most enhanced portion of facial nerve

\begin{tabular}{lc}
\hline \multicolumn{1}{c}{ Portion } & Frequency (\%) \\
\hline Labyrinthine & $16(53.3)$ \\
Genigulate ganglion & $9(30.0)$ \\
Tympanic & $3(10.0)$ \\
Mastoid & $2(6.7)$ \\
\hline
\end{tabular}

평균은 3.4 \pm 0.9 점이었으며 6개월 뒤 $\mathrm{H}-\mathrm{B}$ grade의 평균값은 $1.6 \pm 0.1$ 점이었다. 최초 방문 시 $\mathrm{H}-\mathrm{B}$ Grade III 이하의 환자는 17 명이었으며 이들의 6 개월 뒤 H-B grade의 평균은 $1.11 \pm$ 0.92 , grade IV 이상의 환자는 13 명이었으며 이들의 6개월 뒤 $\mathrm{H}-\mathrm{B}$ grade의 평균은 $2.07 \pm 1.32$ 였다. 대상 환자들을 6 개월 후 에 관찰한 최종 안면마비의 회복도는 House-Brackman grade I 이하로의 완전회복을 보인 경우가 30예 중 15예(50.0\%)였
다. ROI의 ratio가 2 이상으로 병측이 건측에 비해 증강된 예 는 11예(36.7\%)였다. 모든 환자는 안면마비 발생 후 2주 이내 에 측두골 자기공명영상을 촬영하였으며, 안면마비 발생일로 부터 측두골 자기공명영상 촬영일까지 걸린 평균 일수는 $5.30 \pm 3.15$ 일이었다(Table 1).

미로분절(labyrinthine segment)에서 ROI가 측정된 경우가 16명(53.3\%)으로 가장 많았으며 슬신경절(geniculate ganglion)에서 측정된 경우가 9명(30.0\%), 고실부(tympanic segment) 가 3명(10.0\%)으로 뒤를 이었다(Table 2, Figs. 2 and 3).

병측과 건측 조영강도의 비(ROI ratio)와 환자의 initial $\mathrm{H}-\mathrm{B}$ grade와의 상관계수는 $-0.133(p>0.482)$ 으로 유의한 상관관계 가 성립되지 않았다. 또한 조영강도의 비와 6개월 뒤에 평가된 안면마비의 개선 정도(degree of improvement)와의 상관계 
수는 0.111 $(p>0.560)$ 로, 마찬가지로 유의한 상관관계가 없었 다. 안면마비의 발생일로부터 측두골 자기공명영상 촬영까지 걸린 시간과 ROI ratio와의 상관관계는 $0.022(p>0.970)$ 로 역 시 유의한 상관관계를 보이지 않았다(Table 3).

\section{고 찰}

특발성 얼굴신경마비 또는 벨마비는 원인이 될 만한 질환이 나 외상 없이 한쪽의 안면근에 완전 또는 부분적으로 말초성 마비가 발생하는 것으로 말초성 안면마비의 $80 \%$ 가량을 차 지하여 가장 흔한 안면신경마비로 알려져 있다. 발생원인에 대한 가설로는 바이러스 감염이 유력하나 허혈성 혈관질환에 의한 마비, 당뇨에 의한 혈관 장애, 다발성 신경염, 자가면역 질환, 한냉 노출 등의 여러 가설이 존재하며 아직은 논란의 대상이다

Peitersen ${ }^{4}$ 은 25년 동안 1701예의 벨마비와 116예의 이성대

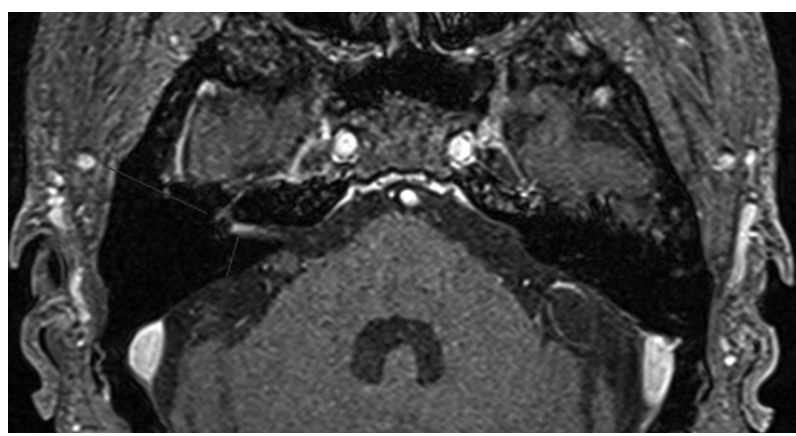

Fig. 2. Magnetic resonance imaging scan showing the mosthighly enhanced portion in labyrinthine segment.
상포진을 대상으로 회복율을 비교분석하였는데, 벨마비의 경우 $71 \%$ 는 완전회복되었고, $12 \%$ 와 $13 \%$ 에서 각각 경도와 중 등도의 후유증을, $4 \%$ 에서는 중증의 후유증을 보여 $83 \%$ 에서 만족할 만한 회복을 보였다고 하였다. 또한 이성대상포진의 경우 $21 \%$ 는 완전회복되었으나, $25 \%$ 가 경도의 후유증을, $26 \%$ 가 중등도의 후유증을, $24 \%$ 가 중증의 후유증을 보였으며 $4 \%$ 는 회복을 보이지 않았다고 하였다.

안면신경마비의 진단에 있어서 청신경종양 등의 다른 기질 적 원인을 배제하기 위하여 자기공명영상을 고려해야 하며, 이 는 뇌간부터 측두골 내, 외분절에 해당하는 안면신경의 전장 을 관찰할 수 있는 가장 유용한 영상의학적 검사이다. ${ }^{12,13)}$

일반적으로 정상인에서도 안면신경의 조영증강이 관찰될 수 있는데 이런 위양성이 자기공명영상의 임상적 유용성을 제한 하는 요인이 될 수 있다. ${ }^{14,15)}$ 정상인에서의 조영증강은 염증 요 인에 의한 것이 아니라 신경 주위의 발달된 혈관총에 의한 것 으로 알려져 있으며 Gebarski 등 ${ }^{12}$ 의 보고에서 정상인 93명 $(\mathrm{n}=186)$ 의 안면신경에 대한 조영증강 분석 결과에서 $69 \%$ 의 환자에서 좌우측이 다른 양상으로 조영증강을 보이고 특히 이 같은 정상적인 조영증강은 혈관총이 발달한 고실분절과 유양 동분절에서 주로 나타난다고 하였다.

벨마비에서 자기공명의 조영증강은 주로 내이도분절의 외 측 부위와 미로분절에서 가장 흔히 나타난다고 보고된 바 있 으나, ${ }^{7,13)}$ 기타 연구에서는 슬상신경절이나 고실분절, 유양동 분절에서 흔히 나타난다고 하여 보고마다 차이가 있다. ${ }^{2,15)}$ 본 연구 결과에서는 벨마비 환자군에서 미로분절이 16예(53.3\%), 슬상신경절이 9예(30\%) 순으로 강한 조영증강을 보였다.

이전의 연구에서 벨마비 환자군 및 귀 대상포진 환자군들

Fig. 3. Magnetic resonance imaging scans showing the most-highly enhanced portion in tympanic segment (A and B).
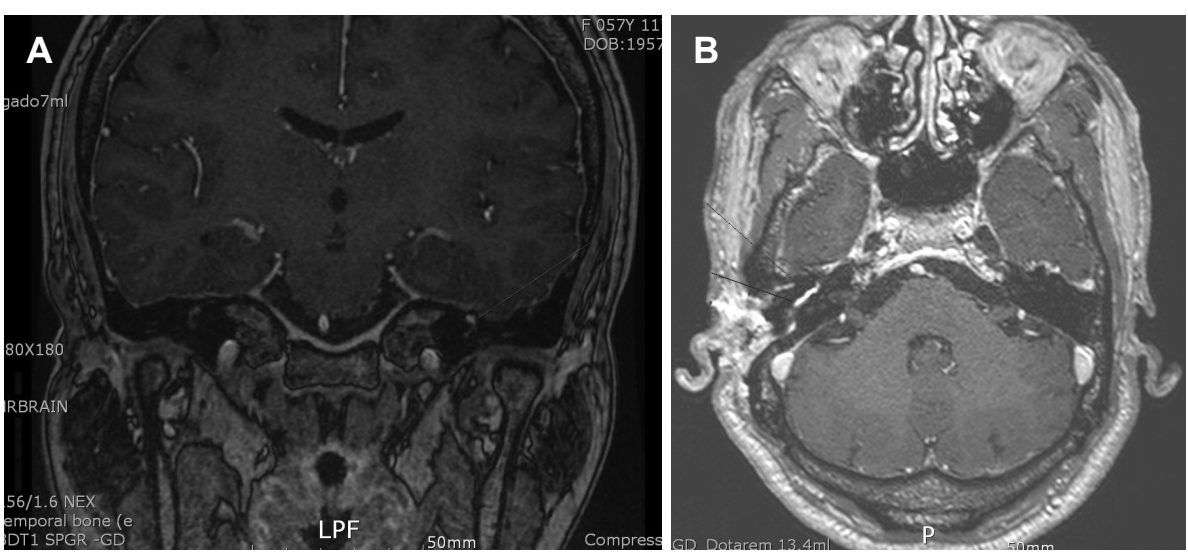

Table 3. Statistical results of ROI ratio vs. initial H-B grade, degree of improvement, and days to imaging

\begin{tabular}{lccc} 
& ROI ratio \& initial H-B grade & ROI ratio \& degree of improvement & ROI ratio \& days to imaging \\
\hline$r^{*}$ & -0.133 & 0.111 & 0.022 \\
p value & 0.482 & 0.560 & 0.970 \\
\hline
\end{tabular}

*Pearson's coefficient of correlation. ROI: region of interest, Initial H-B grade: House-Brackmann grade at initial visit 
을 포함한 안면신경마비 환자들의 자기공명영상에서 조영증 강된 분절의 수와 초기 안면마비의 정도 및 초기 적혈구 침강 속도와 백혈구 수치 등의 사이에서 상관관계를 살펴본 결과 의미 있는 상관관계를 찾을 수 없었다고 보고한 바 있다. ${ }^{16)}$ 또 한 안면신경마비 환자에서 안면신경의 내이도분절 및 미로분 절의 조영강도의 경우 초기 안면마비의 정도와 유의한 연관관 계를 보였다고 보고한 연구에서도, 병변의 위치와 예후와는 유의한 연관성을 찾을 수 없다고 결론 지은 바 있다. ${ }^{17)}$

본 연구에서는 조영증강의 정도를 병측 안면신경부의 최대 조영증강 부위와 건측의 동일 부위를 ROI로 설정하여 이 부 위들의 조영증강도를 비(ratio)로 계산하고 분석하여, 조영제 에 대한 개인적인 특성을 최대한 배제하고 보다 객관적인 평 가를 하고자 하였다. 이전 연구 중에서도 병측의 ROI를 설정 하여 조영강도를 비교한 연구가 있었으나, 이 연구에서는 해당 병측분절의 조영강도는 안면신경의 5 분절(내이도분절, 미로 분절, 슬신경분절, 고실분절, 유양동분절)의 평균에 비교하 여 구하였으며, 조영강도는 예후의 뚜렷한 지표가 되지 못하 였다. ${ }^{18)}$ 본 연구에서도 환자의 initial $\mathrm{H}-\mathrm{B}$ grade, 즉 초기 안면 마비 정도와 $\mathrm{ROI}$ 의 비는 통계학적으로 유의한 상관관계가 없었으며, 6 개월 후에 관찰한 안면마비 개선 정도와도 유의한 상관관계는 성립하지 않았다. 이는 이전에 보고된 연구들에 이어 안면신경마비 환자들의 자기공명영상에서 조영증강의 정도는 환자의 예후를 반영하는 명확한 지표가 되지 않음을 검증하는 결과다.

그러나 자기공명영상에서 조영증강된 안면신경의 분절 부 위를 관찰하는 것은 질병에 따른 안면신경의 해부학적 손상 부위와 그 정도를 파악하는 데 도움을 줄 수 있을 것으로 생 각되며, 이러한 병적 상태의 안면 신경 부위의 해부학적인 이 해를 통해 안면신경 감압술과 같은 수술적 치료의 적응증이 되는 환자에서는 수술적 접근법을 선택하는 데에 그 의의를 찾을 수 있을 것이라 생각된다.

\section{REFERENCES}

1) Hughes GB. Practical management of Bell's palsy. Otolaryngol Head Neck Surg 1990;102(6):658-63.

2) Yetiser $S$, Kazkayas M, Altinok D, Karadeniz Y. Magnetic resonance imaging of the intratemporal facial nerve in idiopathic peripheral facial palsy. Clin Imaging 2003;27(2):77-81.

3) Peitersen E. The natural history of Bell's palsy. Am J Otol 1982;4(2): 107-11.

4) Peitersen E. Bell's palsy: the spontaneous course of 2,500 peripheral facial nerve palsies of different etiologies. Acta Otolaryngol Suppl 2002;(549):4-30.

5) Jonsson L, Tien R, Engström M, Thuomas KA. Gd-DPTA enhanced MRI in Bell's palsy and herpes zoster oticus: an overview and implications for future studies. Acta Otolaryngol 1995;115(5):577-84.

6) Korzec K, Sobol SM, Kubal W, Mester SJ, Winzelberg G, May M. Gadolinium-enhanced magnetic resonance imaging of the facial nerve in herpes zoster oticus and Bell's palsy: clinical implications. Am J Otol 1991;12(3):163-8.

7) Schwaber MK, Larson TC 3rd, Zealear DL, Creasy J. Gadoliniumenhanced magnetic resonance imaging in Bell's palsy. Laryngoscope 1990;100(12):1264-9.

8) Yanagida M, Ushiro K, Yamashita T, Kumazawa T, Katoh T. Enhanced MRI in patients with Ramsay-Hunt's syndrome. Acta Otolaryngol Suppl 1993;500:58-61.

9) Millen SJ, Daniels D, Meyer G. Gadolinium-enhanced magnetic resonance imaging in facial nerve lesions. Otolaryngol Head Neck Surg 1990;102(1):26-33.

10) Tien R, Dillon WP, Jackler RK. Contrast-enhanced MR imaging of the facial nerve in 11 patients with Bell's palsy. AJNR Am J Neuroradiol 1990;11(4):735-41.

11) Nakao Y, Sakihama N, Kumagami H. Vascular permeability changes associated with experimentally induced facial nerve lesions in the rabbit. Eur Arch Otorhinolaryngol 1995;252(4):255-7.

12) Gebarski SS, Telian SA, Niparko JK. Enhancement along the normal facial nerve in the facial canal: MR imaging and anatomic correlation. Radiology 1992;183(2):391-4.

13) Engström M, Abdsaleh $S$, Ahlström H, Johansson L, Stålberg E, Jonsson L. Serial gadolinium-enhanced magnetic resonance imaging and assessment of facial nerve function in Bell's palsy. Otolaryngol Head Neck Surg 1997;117(5):559-66.

14) Jungehuelsing $M$, Sittel $C$, Fischbach $R$, Wagner M, Stennert E. Limitations of magnetic resonance imaging in the evaluation of perineural tumor spread causing facial nerve paralysis. Arch Otolaryngol Head Neck Surg 2000;126(4):506-10.

15) Kinoshita $T$, Ishii $K$, Okitsu T, Okudera $T$, Ogawa T. Facial nerve palsy: evaluation by contrast-enhanced MR imaging. Clin Radiol 2001;56 (11):926-32.

16) Park SN, Kim HS, Jung SL, Park KH, Kim BS, Kwak BK, et al. Magnetic resonance imaging in facial nerve palsy: comparison between Bell's palsy and herpes zoster oticus. Korean J Otolaryngol 2005; 48(7):854-8.

17) Song MH, Kim J, Jeon JH, Cho CI, Yoo EH, Lee WS, et al. Clinical significance of quantitative analysis of facial nerve enhancement on MRI in Bell's palsy. Acta Otolaryngol 2008;128(11):1259-65.

18) Kress BP, Griesbeck F, Efinger K, Solbach T, Gottschalk A, Kornhuber $\mathrm{AW}$, et al. Bell's palsy: what is the prognostic value of measurements of signal intensity increases with contrast enhancement on MRI? Neuroradiology 2002;44(5):428-33. 